\title{
GOIABAS DESIDRATADAS OSMOTICAMENTE SEGUIDAS DE SECAGEM EM ESTUFA $^{1}$
}

\author{
PAULO HENRIQUE MACHADO DE SOUSA ${ }^{2}$ *, GERALDO ARRAES MAIA ${ }^{3}$, MEN DE SÁ MOREIRA DE SOUZA \\ FILHO $^{4}$, RAIMUNDO WILANE DE FIGUEIREDO ${ }^{3}$, ARTHUR CLÁUDIO RODRIGUES DE SOUZA ${ }^{4}$
}

\begin{abstract}
RESUMO - O objetivo deste trabalho foi determinar parâmetros do processo de desidratação osmótica da goiaba, construir as curvas de secagem da fruta pré-tratada através de desidratação osmótica com e sem vácuo e avaliar as características físico-químicas e microbiológicas dos produtos. No final da secagem verificou-se que as goiabas pré-tratadas com osmose à vácuo diminuem o tempo de secagem, reduzindo os gastos com o processo. Observou-se maior escurecimento no produto tratado com osmose sob vácuo nos processos de osmose e de secagem, enquanto a textura não apresentou diferença entre os dois tratamentos. Outro fato relevante foi a ausência de contaminação microbiológica dos dois produtos no final da secagem, sendo a metodologia empregada efetiva na prevenção do desenvolvimento microbiano, concluindo-se que é possível obter goiaba desidratada como produto de umidade intermediária, através de pré-tratamento osmótico seguido de secagem.
\end{abstract}

Termos de Indexação: alimentos de umidade intermediária, Psidium guajava, atividade de água.

\section{GUAVAS PREPARATION BY OSMOTIC DEHYDRATION FOLLOWED BY OVEN DRYING}

\begin{abstract}
The objective of this work was to determine the parameters for the guava osmotic dehydration process, to build the drying curves of the pretreated fruit through osmotic dehydration with and without vacuum and to evaluate the physical chemistry and microbiological characteristics of the products. At the end of the drying process it was verified that the pretreated guavas by osmosis under vacuum reduced the drying time decreasing the expenses with the process. A greater darkening was observed in the treated product with osmosis under vacuum in the osmosis processes and of the drying, while the texture didn't present difference among the two treatments. Another important fact was the absence of microbiological contamination of the two products at the end of the drying process, being the methodology effective in the prevention of the development if microbiological spoilage. It was conclued that is possible to obtain guava dehydrated as product of intermediate humidity, through osmotic pretreatment followed by drying process.
\end{abstract}

Index Terms: intermediate humidity foods, Psidium guajava, water activity.

\section{INTRODUÇÃO}

A goiaba (Psidium guajava, L.) é um dos frutos de maior importância nas regiões subtropicais e tropicais, não só devido ao seu elevado valor nutritivo, mas pela excelente aceitação do consumo "in natura", sua grande aplicação industrial, como também porque pode se desenvolver em condições adversas de clima (Gongatti Netto et al., 1996).

Países como o Brasil, que além da grande variedade de frutas, possui grande disponibilidade de açúcar de cana, o processo de desidratação osmótica pode tornar-se uma alternativa promissora, pois além do baixo custo, proporciona pouca alteração de suas características sensoriais e nutritivas (Falcone \& Suazo, 1988).

A desidratação osmótica comumente ocorre por imersão do produto em soluções de açúcar ou sal. A estrutura complexa da parede celular dos alimentos age como uma membrana semipermeável, a qual não é completamente seletiva, resultando em dois fluxos de transferência de massa em contra-corrente: difusão de água do alimento para a solução e difusão do soluto da solução para o alimento. Em adição, há uma perda dos solutos naturais do produto (açúcares, ácidos orgâni$\cos$, minerais, etc.) que pode ser negligenciável, podendo ter, entretanto, um impacto no seu valor nutricional e sensorial (Heng et al., 1990; Saurel et al., 1994; Azoubel \& Murr, 2000; Kowalska \& Lenart, 2001).

As principais vantagens do processo de desidratação osmótica sobre os processos tradicionais de secagem são: inibição do escurecimento enzimático, com retenção da cor natural sem a utilização de sulfitos, maior retenção de componentes voláteis durante subseqüente secagem e baixo consumo de energia (Maeda \& Loreto, 1998; Pokharkar et al., 1997).

Uma metodologia que está ganhando interesse é a aplicação da desidratação osmótica seguida de secagem (Clydesdale, 1993; Fito et al., 1996; Chiralt et al., 1999) e desidratação osmótica a vácuo, que ocasi- ona uma cinética de perda de água mais rápida, principalmente durante os primeiros períodos do processo (Shi et al., 1995). Neste trabalho visou-se determinar as curvas de secagem e a variação da atividade de água da goiaba pré-tratada através de desidratação osmótica, com e sem utilização de vácuo ao longo do tempo de secagem, além de acompanhar as variações dos atributos coloração e textura durante o processo de secagem.

\section{MATERIALE MÉTODOS}

Goiabas vindas da CEASA, acondicionadas em caixas, previamente protegidas com papel, foram recebidas na planta piloto da EMBRAPA Agroindústria Tropical e selecionadas de acordo com seus atributos de qualidade: coloração da casca amarela, uniformidade, estádio de maturação e isenção de defeitos. Em seguida, foram lavadas por imersão com água clorada ( 50 ppm de cloro ativo/15 min.), descascadas quimicamente com hidróxido de sódio $2 \%$ a $90^{\circ} \mathrm{C}$, seguindo-se a lavagem em água corrente e neutralização com ácido cítrico a $0,25 \%$. Após descascamento, os frutos foram cortados ao meio com o auxílio de facas inox e as sementes foram retiradas com colheres. Depois procedeu-se o branqueamento dos frutos com vapor fluente a $100^{\circ} \mathrm{C}$ por 2 minutos. Em seguida, dividiram-se os frutos em duas partes, sendo a primeira imersa em xarope e ambas colocadas em xarope de sacarose a $65^{\circ}$ Brix e proporção fruto:xarope $1: 2$ a $65^{\circ} \mathrm{C}$ durante 2 horas. $\mathrm{Na}$ formulação do xarope empregado na osmose, adicionaram-se 300ppm de ácido ascórbico, 1.000 ppm de benzoato de sódio como conservante e ácido cítrico para o ajuste do $\mathrm{pH}$ do xarope até $\mathrm{pH} 3$.

Decorrida a osmose, realizou-se a secagem em estufa com circulação de ar forçada da marca MARCONI, modelo MA 035 , a $65^{\circ} \mathrm{C} \pm 5^{\circ}$ $\mathrm{C}$ até atingir valores de atividade de água (Aw) menores que 0,75 . Os produtos obtidos foram embalados em recipientes retangulares de

\footnotetext{
${ }^{1}$ (Trabalho 037/2003). Recebido: 26/02/2003. Aceito para publicação: 11/09/2003.

${ }_{2}^{2}$ Bolsista FUNCAP / Universidade Federal do Ceará - Rua Sílvio Romero, 84 - Álvaro Weyne. CEP: 60336-100 - Fortaleza-CE - Fone: 85 2282031. E-mail: phmachado@uol.com.br

${ }^{3}$ Universidade Federal do Ceará - UFC - Cx Postal 12168. CEP 60356-000 - Fortaleza-CE. Fone: 85 2889752. E-mail: frutos@ufc.br

${ }^{4}$ Embrapa Agroindústria Tropical - Rua Dra Sara Mesquita, 2270 - Planalto Pici. Cep: 60511-110 - Fortaleza-CE - Fone: 85 299 1849. E-mail: sa@cnpat.embrapa.br

* Aquem a correspondência deve ser enviada.
} 
polietileno tereftalatado (PET) transparentes, com tampa (Neoform $\subset$ N-94) e capacidade para $200 \mathrm{~g}$ do produto. Durante cada experimento (mantido sob osmose sem utilização de vácuo e submetido à osmose com utilização de vácuo) foram retiradas amostras em triplicata (seis pedaços por amostra) antes e depois da osmose e a cada intervalo de duas horas de secagem, com o objetivo de levantar as características de atividade de água (instrumental Aqualab CX-2 Decagon); umidade de acordo com Aoac (1992); teor de sólidos solúveis totais (em refratômetro de bancada modelo ABBÉ) (Instituto Adolfo Lutz, 1985); coloração determinada em colorímetro Minolta Color Meter-CR300, expressa como valor $\mathrm{L}^{*}$ (luminosidade) e textura instrumental em equipamento Analyser Stable TX-2. e microbiológicas de contagem padrão, bolores e leveduras, coliformes totais e fecais e Salmonella sp de acordo com APHA (2001).

\section{RESULTADOS E DISCUSSÃO}

Verifica-se nas figuras 1 e 2 que os valores de umidade e Aw no final da osmose foram respectivamente de $55,46 \%$ e 0,948 , quando se empregou o xarope de $65^{\circ}$ Brix sem vácuo e $32,04 \%$ e 0,892 com o xarope de $65^{\circ}$ Brix com utilização de vácuo. Constata-se haver durante a osmose uma influência da pressão exercida pelo sistema sobre a redução da umidade e Aw, sendo esta aumentada com a utilização do vácuo.

Resultados semelhantes foram observados quando se trabalhou com abacaxi, abricó e morango (Shi et al., 1995), banana (Sousa, 2002) e manga (Souza Neto, 2002); onde em todos os trabalhos observou-se que o tratamento a vácuo ocasionou maior perda de água quando comparado com o tratamento sem a utilização de vácuo.

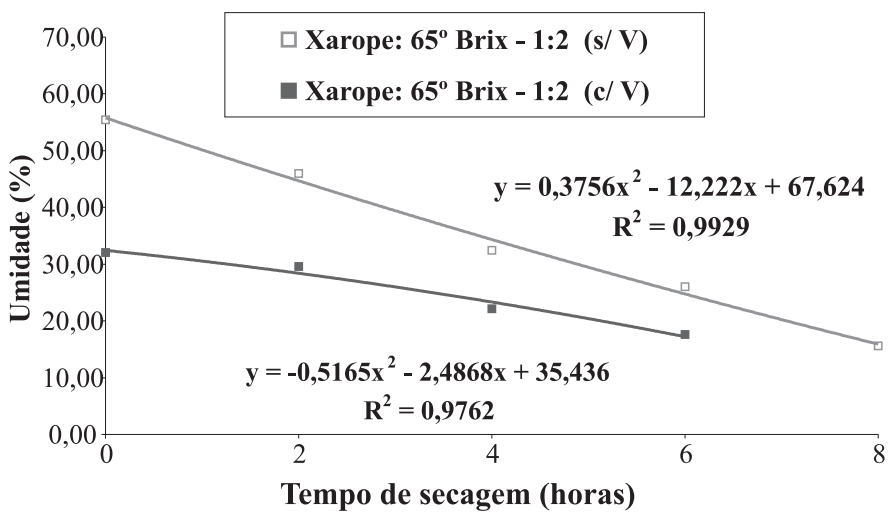

FIGURA 1 - Efeito do tempo de secagem sobre a umidade em pedaços de goiaba pré-tratada por osmose sem utilização de vácuo (s/V) e com utilização de vácuo (c/V).

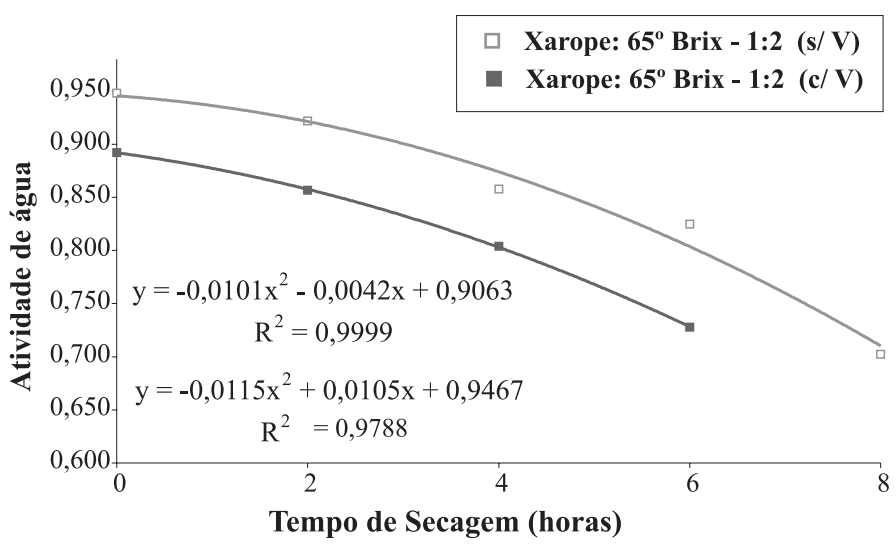

FIGURA 2 - Efeito do tempo de secagem sobre a atividade de água em pedaços de goiaba pré-tratada por osmose sem utilização de vácuo (s/V) e com utilização de vácuo (c/V).
Observou-se a atividade de água desejada ou seja, Aw menor que 0,75 , valor que se encontra na faixa de alimentos de umidade intermediária, que varia de 0,65 a 0,85 (Karel, 1975), foi atingida mais rapidamente nos produto tratado previamente com osmose a vácuo do que os produtos tratados sem utilização de vácuo, sendo de 8 horas para o tratamento sem vácuo e de 6 horas para o tratamento com vácuo. O teor de sólidos solúveis totais também aumentou bastante após o processo de osmose, o equivalente ao tempo zero do processo de secagem, principalmente para o tratamento com vácuo (Figura 3). Esta tendência durante a osmose é explicada pela maior absorção de sólidos solúveis e mais rápida perda de água, com a conseqüente redução de Aw, uma vez que o vácuo acentua as trocas difusionais e a pressão osmótica sobre o tecido do fruto.

Com relação à coloração (Figura 4), no final da osmose e da secagem, verificou-se uma maior tendência ao escurecimento (redução do valor $\mathrm{L}^{*}$ ) com o incremento da concentração do xarope osmótico, visto que os valores de $\mathrm{L}^{*}$ variam de 0 (claro) ao 100 (totalmente escuro). As mudanças de coloração (valor L) podem ser explicadas pela absorção de açúcares durante a osmose e o incremento dos mesmos durante a secagem, bem como pelo efeito da temperatura que favorece processos de escurecimento, como a reação de Maillard e a caramelização.

Para a textura (Figura 5), a mesma apresentou valores de força de corte, dados em Newton $(\mathrm{N})$, finais de 23,4 N para o tratamento sem utilização de vácuo e $36,4 \mathrm{~N}$ para o tratamento a vácuo após a osmose, e de 221,1 N para o tratamento sem utilização de vácuo e $227,7 \mathrm{~N}$ para o tratamento a vácuo após a secagem, observando-se um aumento da textura com o tempo de secagem, o que pode ser justificado pela perda de água e concentração dos sólidos solúveis (Figura 3).

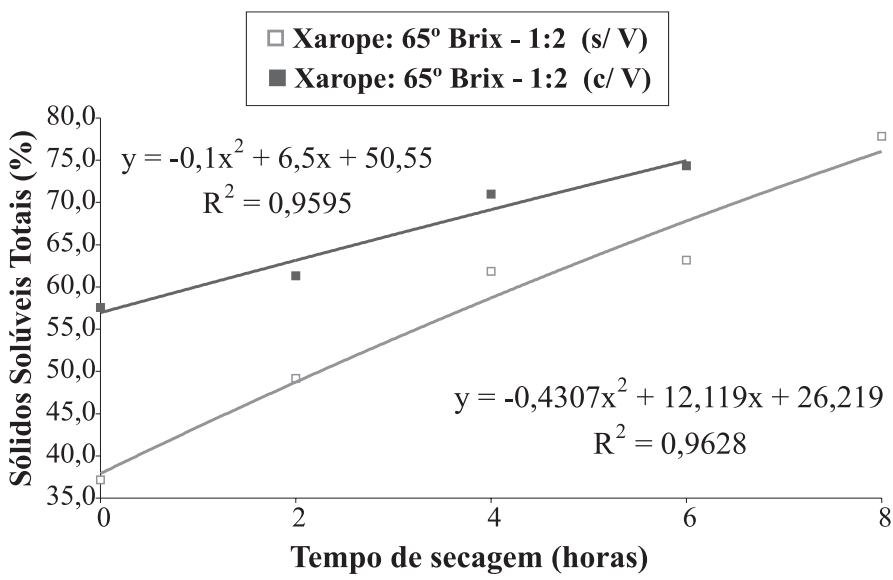

FIGURA 3 - Efeito do tempo de secagem sobre a concentração de sólidos solúveis em pedaços de goiaba pré-tratada por osmose sem utilização de vácuo (s/V) e com utilização de vácuo $(\mathrm{c} / \mathrm{V})$.

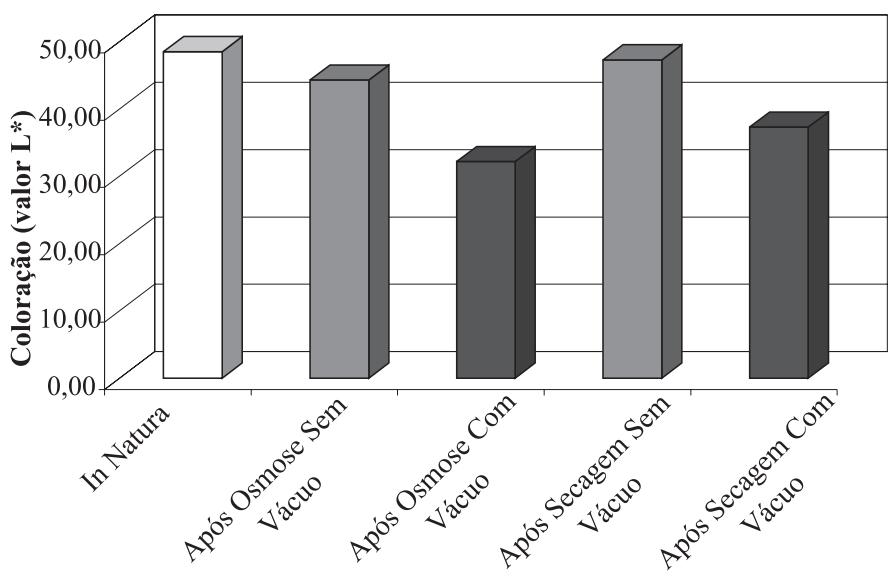

FIGURA 4 - Escurecimento (valor L*) dos pedaços de goiabas in natura e após os processos de osmose e secagem. 


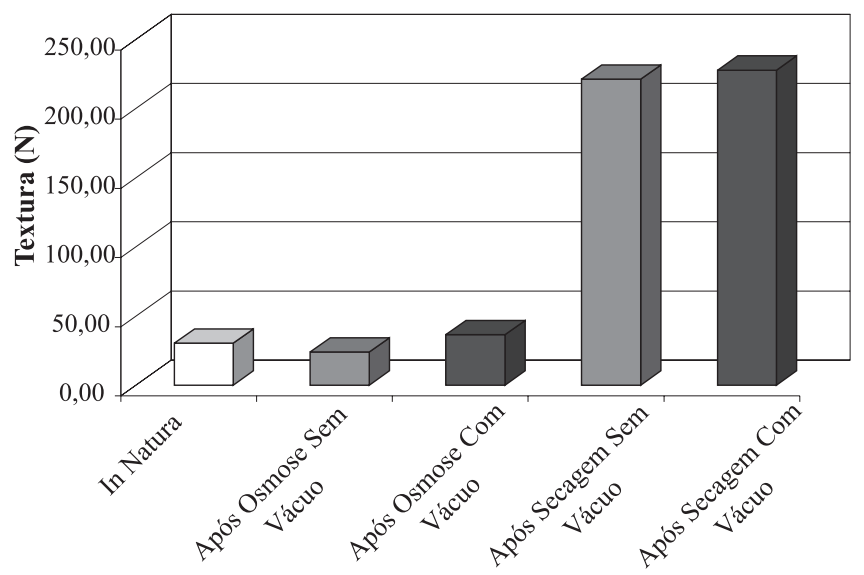

FIGURA 5 - Textura (Força de corte) de pedaços de goiaba in natura e após os processos de osmose e secagem.

Os produtos apresentaram contagem de microrganismos aeróbios mesófilos inferiores a $10 \mathrm{UFC/g}$, bolores e leveduras inferiores a $10 \mathrm{UFC} / \mathrm{g}$. As determinações de coliformes totais (Coliformes a $\left.35^{\circ} \mathrm{C}\right) \mathrm{e}$ coliformes fecais (Coliformes a $45^{\circ} \mathrm{C}$ ) apresentaram valores inferiores a 3 $\mathrm{NMP} / \mathrm{g}$. A presença de Salmonella sp não foi detectada nas amostras avaliadas. Portanto, as amostras atenderam aos padrões estabelecidos pela legislação federal vigente (BRASIL, 2001), que estabelece os seguintes padrões microbiológicos sanitários para frutas desidratadas com adição de açúcares: máximo de $10^{2} \mathrm{NMP} / g$ para coliformes fecais $\left(45^{\circ} \mathrm{C}\right)$ e ausência de Salmonella sp em $25 \mathrm{~g}$ do produto.

Estes resultados encontrados após o processamento e durante o armazenamento podem ser atribuídos à presença de aditivos como benzoato de sódio $(0,1 \%)$ e ácido cítrico, além da baixa Aa, o que tornam as condições desfavoráveis para o desenvolvimento para a maioria dos microrganismos.

\section{CONCLUSÕES}

1) As características do produto são influenciadas pela pressão de trabalho utilizada durante a osmose, sendo o vácuo responsável pela diminuição do tempo de secagem.

2) A análise microbiológica realizada indicou que os produtos de goiaba desidratados por pré-tratamento osmótico seguido de secagem em estufa foram processados em condições higiênico-sanitárias adequadas, contribuindo para a segurança do produto, sendo a metodologia empregada efetiva na prevenção do desenvolvimento microbiano.

3) Assim, é possível obter goiaba desidratada, como produto de umidade intermediária, através de pré-tratamento osmótico seguido de secagem.

\section{REFERÊNCIA BIBLIOGRÁFICAS}

AOAC (ASSOCIATION OF OFFICIAL ANALITICAL CHEMISTRY). Official methods of analysis of the association of official analytical chemistry. 12 ed. Washington, 1992.

APHA (AMERICAN PUBLIC HEALTH ASSOCIATION). Compendium of methods for the microbiological examination of foods. Washington, DC, 2001.676p.

AZOUBEL, P.M.; MURR, F.E. Mathematical modelling of the osmotic dehydration of cherry tomato. Ciência e Tecnologia de Alimentos, Campinas, v. 20, n. 2, p. 228-232, 2000.

BRASIL, Resolução RDC n. ${ }^{\circ}$ 12, de 02 de janeiro de 2001. Dispõe sobre os princípios gerais para o estabelecimento de critérios e padrões microbiológicos para alimentos. Agência Nacional de Vigilância Sanitária (ANVISA). Disponível em: http:// www.vigilanciasanitaria.gov.br/anvisa.html>. Acesso em: 20 ago. 2001.

CHIRALT, A. et al. Vacuum impregnation: A tool in minimally processing of foods. In: OLIVEIRA, F.A.R.; OLIVEIRA, J.C. (Ed.) Processing of food: quality optimization and process assessment, Boca Raton, FL: RCR Press, 1999. p. 341-356

CLYDESDALE, F.M. Color as a factor choice. Critical Review in Food Science and Nutrition, Boca Raton, v. 33, n. 1, p. 83-101, 1993.

FALCONE, M.A.; SUAZO, V.A.T. Desidratação osmótica do abacaxi (Ananas comosus L.). Parte I. Boletim da SBCTA, Campinas, v. 22, n. $1 / 2$, p. $17-35,1988$.

FITO, P. et al. Coupling of hydrodynamic mechanism and deformationrelaxation phenomena during vacuum treatments in solid porous food-liquid systems. Journal of Food Engineering, Kidling, v. 21, p. 229-240, 1996.

GONGATTI NETTO, A.; GARCIA, A.E.; ARDITO, E.F.G. et al. Goiaba para exportação: procedimentos de colheita e pós-colheita, Brasília: EMBRAPA - SPI, 1996. 35p.: il. (Publicações Técnicas FRUPEX; 20).

HENG, W.; GUILBERT, S.; CUQ, J.L. Osmotic dehydration of papaya: influence of process variables on the quality. Sciences des Aliments, Kanagawa, v. 10, p. 831-848, 1990.

KAREL, M. Osmotic drying. In: FENNEMA, O. Principles of food science. New York: [s.n], 1975. part 2, p. 348-357

KOWALSKA, H.; LENART, A. Mass exchange during osmotic pretreatment of vegetables. Journal of Food Engineering, Kidling, n. 49, p. 137-140, 2001.

MAEDA, M.; LORETO, R.L. Desidratação osmótica de bananas. Semina: Ci. Agr., Londrina, v. 19, n.1, p.60-67, mar. 1998.

POKHARKAR, S.M.; PRASAD, S.; DAS, H. A Model for osmotic concentration of bananas slices. Journal Food Science and Technology, Mysore, v. 34, n. 3, p. 230-232, 1997.

SAUREL, R. et al. Mass transfer phenomena during osmotic dehydration of apple. I. Fresh plant tissue. International Journal of Food Science \& Technology, Oxford, n. 29, p. 531-542, 1994.

SHI, X.Q.; FITO, P.; CHIRALT, A. Influence of vacuum treatment on mass transfer during osmotic dehydration of fruits. Food Research International, Kidlington, v. 28, n. 5, p. 445-54, 1995.

SOUSA, P.H.M. "Desidratação osmótica de banana com e sem vácuo com complemento de secagem em estufa de circulação de ar". 2002. 90f. Dissertação (Mestrado) - Universidade Federal do Ceará, Fortaleza, 2002.

SOUZA NETO, M.A. "Desidratação osmótica de manga coité com e sem utilização de vácuo com complemento de secagem em estufa". 2002. 67f. Dissertação (Mestrado) - Universidade Federal do Ceará, Fortaleza, 2002. 